УДК 519.222

\title{
STATISTICAL ANALYSIS OF OPTICAL IMAGES OF VEGETABLE ASSEMBLIES
}

\author{
V. Lisenko, N. Zaiets, O. Oprishko, D. Komarchuk \\ National University of Life and Environmental Sciences of Ukraine
}

\begin{tabular}{|c|c|}
\hline Key words: & ABSTRACT \\
\hline $\begin{array}{l}\text { Pattern recognition } \\
\text { Spectral characteristics } \\
\text { Additive color model } \\
\text { Average } \\
\text { Mod } \\
\text { Median } \\
\text { Correlation } \\
\text { Normal distribution }\end{array}$ & \multirow{3}{*}{$\begin{array}{l}\text { In the article it is shown that for the operative estimation and } \\
\text { analysis of optical images of objects of plants using spectral } \\
\text { characteristics in the optical range, data have considerable } \\
\text { volumes. The data is represented by an additive color model } \\
\text { in RGB format, which requires significant numerable } \\
\text { resources for their use in neural networks. It is proposed } \\
\text { instead of a large sample size on the input of the neural } \\
\text { network to provide statistical characteristics of the sample, } \\
\text { which reduces the numerable resource, while adequately } \\
\text { representing the image. }\end{array}$} \\
\hline $\begin{array}{l}\quad \text { Article history: } \\
\text { Received } 10.11 .2017 \\
\text { Received in revised form } \\
05.12 .2017 \\
\text { Accepted } 26.12 .2017\end{array}$ & \\
\hline $\begin{array}{l}\text { Corresponding author: } \\
\text { V. Lisenko } \\
\text { E-mail: } \\
\text { npnuht@ukr.net }\end{array}$ & \\
\hline
\end{tabular}

DOI: $10.24263 / 2225-2924-2017-23-6-4$

\section{СТАТИСТИЧНИЙ АНАЛІЗ ОПТИЧНИХ ОБРАЗІВ ОБ'ЄКТІВ РОСЛИННИХ НАСАДЖЕНЬ}

\section{В.П. Лисенко, Н.А. Заєщь, О.О. Опришко, Д.С. Комарчук \\ Національний університет біоресурсів і природокористування Украӥни}

У статті показано, щзо для оперативної оцінки та аналізу оптичних образів об'єктів рослинних насаджень із використанням спектральних характеристик в оптичному діапазоні, обсяги даних, представлених адитивною моделлю кольорів у форматі $R G B$, досить значні, що потребує суттєвих обчислювальних ресурсів для їх використання в нейронних мережсах. Пропонується замість значної за обсягами вибірки на вхід нейронної мережі подавати статистичні характеристики вибірки, що скорочує обчислювальний ресурс, адекватно представляючи при цьвому зображення.

Ключові слова: розпізнавання образів, спектральні характеристики, адитивна модель кольорів, середнє, мода, медіана, кореляиія, нормальний розподіл.

Постановка проблеми. 3 розвитком обчислювальної техніки стало можливим вирішити ряд завдань, що виникають у процесі управління об'єктами 
аграрного спрямування, та дають можливість полегшити, прискорити, підвищити якість результату. Для оперативної оцінки станів рослинних насаджень потрібно створити систему розпізнавання образів, що дасть змогу оцінити оптичний образ досліджуваного об’єкта в комплексі системи дистанційного моніторингу станів посівів.

Аналіз останніх досліджень і публікацій. Розроблювана система дистанційного моніторингу станів посівів використовуватиметься при вирощуванні зернових культур (пшениці та кукурудзи) та створенні електронної мапи стану азотного (фосфорного, калійного) живлення рослин, а також при створенні й коригуванні існуючих агрохімічних картограм, коригуванні норм і доз добрив. Існує три групи методів розпізнавання образів [1]:

1. Порівняння із зразком: класифікація за найближчим середнім, класифікація за відстанню до найближчого сусіда та структурні методи розпізнавання.

2. Статистичні методи: використовують певну статистичну інформацію при вирішенні задачі розпізнавання. Метод визначає приналежність об'єкта до конкретного класу на основі ймовірності. В ряді випадків це зводиться до визначення апостеріорної ймовірності приналежності об'єкта до певного класу, за умови, що ознаки цього об'єкта мають відповідні значення.

3. Нейронні мережі. Окремий клас методів розпізнавання, характерною особливістю яких є здатність навчатися.

Очевидно, що використання методів розпізнавання образів, що відносяться до першої та другої групи, в нашому випадку неефективні, оскільки в процесі зміни типу насаджень потрібно буде змінювати і програмне забезпечення розроблюваної системи. Перевагою нейронних мереж перед традиційними алгоритмами $\epsilon$ можливість їх навчання в процесі роботи.

Мета дослідження: провести статистичний аналіз оптичних образів об'єктів рослинних насаджень для зменшення об'єму вибірки вхідних даних, що представлені адитивною моделлю кольорів у форматі RGB.

Матеріали і методика. Нейронна мережа (НM), яка застосовується для аналізу оптичних образів об'єктів рослинних насаджень, являє собою математичну модель паралельних обчислень, що містить взаємодіючі між собою прості процесорні елементи - штучні нейрони.

Для оперативної оцінки та аналізу оптичних образів об'єктів рослинних насаджень (полів) із використанням спектральних характеристик в оптичному діапазоні розбиваємо отримане зображення на частини площею $10 \times 10$ метрів. Розмір площі визначається виходячи 3 технологічних габаритів машини внесення добрив і може коригуватися залежно від типу та марки обладнання. За результатами попередніх досліджень визначена оптимальна висота зйомки 100 - 120 м над полем. При масштабуванні отриманого зображення розмір площі внесення добрив $10 \times 10$ метрів відповідає розширенню розміром $128 \times 128$ пікселів. Обсяги даних представлені адитивною моделлю кольорів в форматі RGB. При переведенні зображення у векторну форму отримаємо вибірку достатньо великим об'ємом: $128 \times 128 \times 3=49152$ комірки даних. 3 огляду на те, що для обробки та аналізу такого об'єму даних витрачається багато ресурсів і часу, виникає необхідність використання методів статистичного аналізу отриманих результатів адекватних завданню. 
Проведемо розрахунок статистичних показників, які дають змогу оцінити максимальний і мінімальний елементи вибірки, середнє значення, медіану, моду, взаємний вплив аналізованих факторів та інші описові статистики. Головним завданням описової статистики є надання стислої та концентрованої інформації аналізу даних у числовому і графічному вигляді [3;4].

Показники описової статистики можна розподілити на кілька груп:

- показники стану, що описують стан експериментальних даних на числовій осі. Приклади таких даних — максимальний і мінімальний елементи вибірки, середнє значення, медіана, мода тощо;

- показники розкиду, що описують ступінь розкиду даних щодо центральної тенденції. До них відносяться вибіркова дисперсія, різниця між мінімальним і максимальним елементами (розмах, інтервал вибірки) тощо;

- показники асиметрії: положення медіани щодо середнього тощо;

- графічні представлення результатів: гістограма, частотна діаграма тощо.

Дані показники використовуються для наочного уявлення й аналізу результатів усієї дослідницької вибірки, експериментальної та контрольної групи. При використанні описової статистики важливо враховувати тип даних i параметри розподілу.

У статистиці такі показники розподілу як середнє, мода та медіана називають мірами центральної тенденції. Вони показують загальні характеристики розподілу даних за певною змінною, дають змогу виявити одне значення, що описує весь розподіл. Можна також сказати, що середнє, мода та медіана — це окремі значення, що представляють весь набір даних, типові для всіх значень у групі.

Міри центральної тенденції потрібні, щоб отримати загальну картину розподілу, отримати чітку картину даних, що досліджуються, та використовувати отримані дані при побудові нейронної мережі для визначення стану живлення рослин на основі отриманих оптичних образів.

Найвідомішою мірою центральної тенденції (і найбільш вживаною в повсякденному побуті) є середнє значення ряду даних. Кожне значення дає внесок у визначення середнього значення, коли поширення значень $є$ симетричними довкола центральної точки. Середнє значення більш стабільне, ніж медіана чи мода. Тому, коли потрібно знайти найбільш стабільну міру центральної тенденції, використовують середнє.

Коли екстремальні значення впливають на середнє, медіана є найкращою мірою центральної тенденції. Медіану використовують, коли потрібно, щоб певні значення впливали на центральну тенденцію, але все, що про них відомо, це те, що вони «нижчі» або «вищі» за медіану. Недоліком використання медіани є те, що вона не так жорстко визначена, як середнє, оскільки іiі значення не вираховується, а знаходиться серед значень у розподілі. Також із медіаною потім не можна робити алгебраїчні перетворення, як із середнім.

Мода використовується, коли потрібна швидка і приблизна міра центральної тенденції. Вона не включає до розрахунку всі спостереження розподілу, а лише концентрацію частот. На моду ніколи не впливають екстремальні значення в розподілі, а лише екстремальні частоти значень, наскільки часто 
те чи інше значення змінної зустрічається в розподілі. На відміну від середнього, подальші алгебраїчні перетворення моди неможливі.

Результати і обговорення. Для статистичного аналізу даних використаємо пакет прикладних програм STATISTICA, розроблений компанією StatSoft. У таблицях, наведених на рис. 1, 2, 3, змінні Var1, Var2 та Var3 відповідають числовим значенням адитивної моделі кольорів у форматі RGB: Var1 - R, Var2 - G та Var3 - B.

Розподіл, у якому всі три міри центральної тенденції збігаються, тобто середнє дорівнює медіані і дорівнює моді, називається нормальним [3; 4]. Для визначення характеру розподілу вхідних змінних визначимо частоту коливання їх значень. Частота коливання - це абсолютні числа, що показують стільки раз у сукупності зустрічається дане вхідне значення параметра.

\begin{tabular}{|c|c|c|c|c|c|c|}
\hline \multirow[b]{2}{*}{ Группа } & \multicolumn{6}{|c|}{$\begin{array}{l}\text { Таблица частот: Var1 (stat_analiz.sta) } \\
\text { K-C d=,02257, }<<, 01 \text {;Лиллиефорса } \mathrm{p}<, 01\end{array}$} \\
\hline & Частота & $\begin{array}{l}\text { Кумул. } \\
\text { частота }\end{array}$ & $\begin{array}{l}\text { Процент } \\
\text { допуст. }\end{array}$ & $\begin{array}{l}\text { Кумул. \% } \\
\text { допуст. }\end{array}$ & $\begin{array}{l}\text { \% всех } \\
\text { наблюд. }\end{array}$ & $\begin{array}{l}\text { Кумул. \% } \\
\text { от всех }\end{array}$ \\
\hline$-50,0000<x<=0,000000$ & 0 & 0 & 0,00000 & 0,0000 & 0,00000 & 0,0000 \\
\hline $0,000000<x<=50,00000$ & $\overline{6636}$ & 636 & 1,93897 & 1,9390 & 1,93891 & 1,9389 \\
\hline $50,00000<x<=100,0000$ & 13031 & 13667 & 39,72745 & 41,6664 & 39,72624 & 41,6651 \\
\hline $100,0000<x<=150,0000$ & 17202 & 30869 & 52,44352 & 94,1099 & 52,44192 & 94,1071 \\
\hline $150,0000<x<=200,0000$ & 1878 & 32747 & 5,72544 & 99,8354 & 5,72526 & 99,8323 \\
\hline $200,0000<x<=250,0000$ & 13 & 32760 & 0,03963 & 99,8750 & 0,03963 & 99,8720 \\
\hline $250,0000<x<=300,0000$ & 41 & 32801 & 0,12500 & 100,0000 & 0,12499 & 99,9970 \\
\hline Пропущ. & 1 & 32802 & 0,00305 & & 0,00305 & 100,0000 \\
\hline
\end{tabular}

Рис. 1. Таблиця частот коливання значень змінної Var1

\begin{tabular}{|c|c|c|c|c|c|c|}
\hline \multirow[b]{2}{*}{ Группа } & \multicolumn{6}{|c|}{$\begin{array}{l}\text { Таблица частот: Var2 (stat_analiz.sta) } \\
\text { K-C d=,01653, }<<, 01 ; \text { Лиллиефорса } \mathrm{p}<, 01 \\
\end{array}$} \\
\hline & Частота & \begin{tabular}{|l|} 
Кумул. \\
частота
\end{tabular} & \begin{tabular}{|c|} 
Процент \\
допуст.
\end{tabular} & $\begin{array}{l}\text { Кумул. \% } \\
\text { допуст. }\end{array}$ & $\begin{array}{l}\text { \% всех } \\
\text { наблюд. }\end{array}$ & $\begin{array}{l}\text { Кумул. \% } \\
\text { от всех }\end{array}$ \\
\hline$-50,0000<x<=0,000000$ & 0 & 0 & 0,00000 & 0,0000 & 0,00000 & 0,0000 \\
\hline $0,000000<x<=50,00000$ & 62 & 62 & 0,18902 & 0,1890 & 0,18901 & 0,1890 \\
\hline $50,00000<x<=100,0000$ & 4595 & 4657 & 14,00872 & 14,1977 & 14,00829 & 14,1973 \\
\hline $100,0000<x<=150,0000$ & 21289 & 25946 & 64,90351 & 79,1012 & 64,90153 & 79,0988 \\
\hline $150,0000<x<=200,0000$ & 6626 & 32572 & 20,20060 & 99,3019 & 20,19999 & 99,2988 \\
\hline $200,0000<x<=250,0000$ & 188 & 32760 & 0,57315 & 99,8750 & 0,57314 & 99,8720 \\
\hline $250,0000<x<=300,0000$ & 41 & 32801 & 0,12500 & 100,0000 & 0,12499 & 99,9970 \\
\hline Пропущ. & 1 & 32802 & 0,00305 & & 0,00305 & 100,0000 \\
\hline
\end{tabular}

Рис. 2. Таблиця частот коливання значень змінної Var2

\begin{tabular}{|c|c|c|c|c|c|c|}
\hline \multirow[b]{2}{*}{ Группа } & \multicolumn{6}{|c|}{$\begin{array}{l}\text { Таблица частот: Var3 (stat_analiz.sta) } \\
\text { K-C d=,05455, p<,01;Лиллиефорса } p<, 01\end{array}$} \\
\hline & Частота & $\begin{array}{l}\text { Кумул. } \\
\text { частота }\end{array}$ & $\begin{array}{c}\text { Процент } \\
\text { допуст. }\end{array}$ & $\begin{array}{l}\text { Кумул. \% } \\
\text { допуст. }\end{array}$ & $\begin{array}{r}\text { \% всех } \\
\text { наблюд. }\end{array}$ & $\begin{array}{l}\text { Кумул. } \% \\
\text { от всех }\end{array}$ \\
\hline$-50,0000<x<=0,000000$ & 35 & 35 & 0,10670 & 0,1067 & 0,10670 & 0,1067 \\
\hline $0,000000<x<=50,00000$ & 4450 & 4485 & 13,56666 & 13,6734 & 13,56625 & 13,6729 \\
\hline $50,00000<x<=100,0000$ & 23507 & 27992 & 71,66550 & 85,3389 & 71,66331 & 85,3363 \\
\hline $100,0000<x<=150,0000$ & 4615 & 32607 & 14,06969 & 99,4086 & 14,06926 & 99,4055 \\
\hline $150,0000<x<=200,0000$ & 152 & 32759 & 0,46340 & 99,8720 & 0,46339 & 99,8689 \\
\hline $200,0000<x<=250,0000$ & 1 & 32760 & 0,00305 & 99,8750 & 0,00305 & 99,8720 \\
\hline $250,0000<x<=300,0000$ & 41 & 32801 & 0,12500 & 100,0000 & 0,12499 & 99,9970 \\
\hline Пропущ. & 1 & 32802 & 0,00305 & & 0,00305 & 100,0000 \\
\hline
\end{tabular}

Рис. 3. Таблиця частот коливання значень змінної Var3 
Найбільш часто вживаними критеріями для перевірки гіпотези про закон розподілу є критерій Пірсона, так звана лінійна кореляція, що показує ступінь лінійних зв'язків між змінними. На діаграмі (рис. 4) показано графіки кореляції між Var1, Var2 та Var3. Коефіцієнти кореляції (безрозмірна величина, що не залежить від масштабу вимірювань) у нашому випадку знаходяться в межах $0,8-0,9$, що свідчить про тісний зв'язок між вхідними даними.
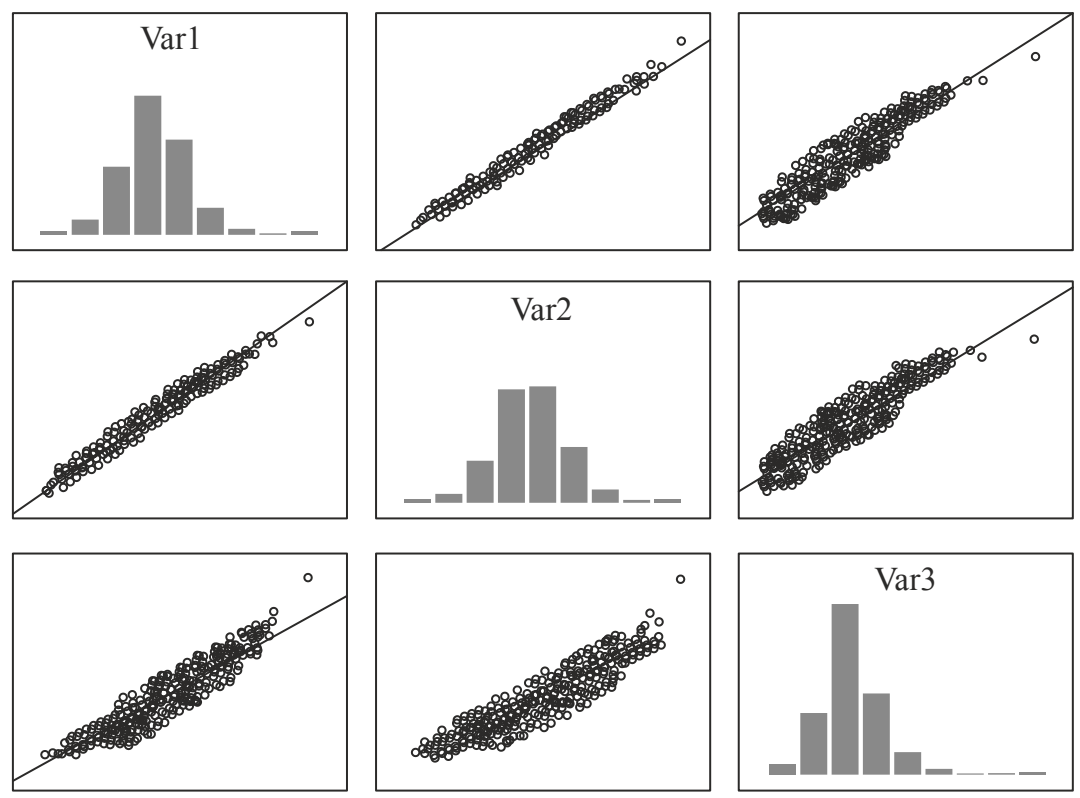

Рис. 4. Діаграма кореляції змінних Var1, Var2 і Var3

Нормальний (або гаусовий) розподіл має дзвіноподібну форму, абсолютно симетричну щодо осі, яка проходить через середне значення і математично описується формулою, що включає два параметри: середнє і стандартне відхилення. Характерна властивість нормального розподілу полягає в тому, що $68 \%$ усіх спостережень лежить у діапазоні 1, а діапазон 2 стандартних відхилень включає 95\% даних.

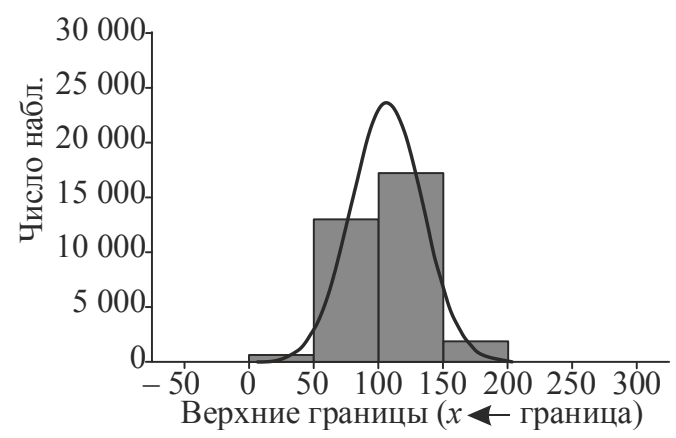

Рис. 5. Графік щільності нормального розподілу змінної Var1 


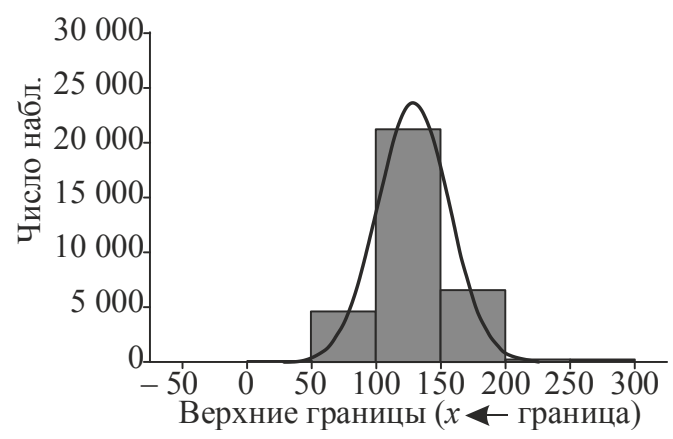

Рис. 6. Графік щільності нормального розподілу змінної Var2

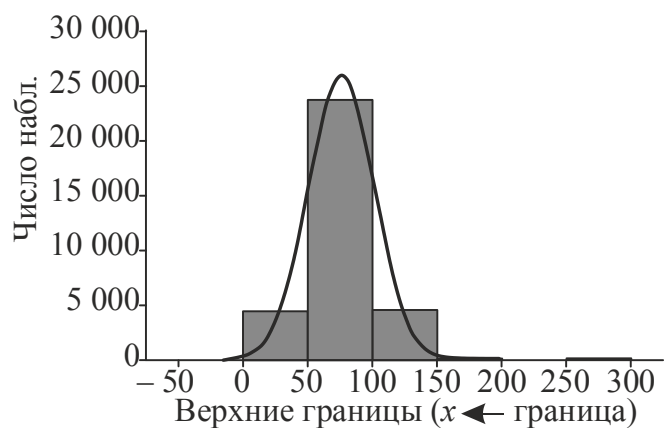

Рис. 7. Графік щільності нормального розподілу змінної Var3

\begin{tabular}{|c|c|c|c|c|c|c|c|c|c|c|}
\hline \multirow[b]{2}{*}{ Переменная } & \multicolumn{10}{|c|}{ Описательные статистики (stat_analiz.sta) } \\
\hline & N набл. & Среднее & Медиана & Мода & $\begin{array}{c}\text { Частота } \\
\text { моды }\end{array}$ & Минимум & Максимум & Дисперс. & Стд. откл. & \begin{tabular}{|l} 
Станд. \\
Ошибка
\end{tabular} \\
\hline Var1 & 32801 & 106,8078 & 106,0000 & 102,0000 & 514 & 3,00000 & 255,0000 & 765,6944 & 27,67118 & 0,152786 \\
\hline Var2 & 32801 & 129,1260 & 129,0000 & 121,0000 & 516 & 23,00000 & 255,0000 & 757,9619 & 27,53111 & 0,152013 \\
\hline Var3 & 32801 & 75,6190 & 74,0000 & 73,00000 & 653 & 0,00000 & 255,0000 & 651,6346 & 25,52713 & 0,140948 \\
\hline
\end{tabular}

Рис. 8. Таблиця описових статистик аналізу даних

При аналізі розподілу вхідних даних показано, що три міри центральної тенденції збігаються, тобто середнє практично дорівнює медіані і моді (Var1 106,8; 106; 102; Var2 - 129,1;129; 121; Var3 - 75,6; 74; 73 ), а отже, всі вхідні дані розподілені за нормальним законом.

За результатами статистичного аналізу оптичних образів об'єктів рослинних насаджень показано, що всі три вхідні параметри, які описують стан сільськогосподарських насаджень, розподілені за нормальним законом. Нормальний розподіл у нашому випадку важливий тому, що замість вибірки великого об'єму набору даних на вхід нейронної мережі можна подати лише статистичні характеристики отриманої адитивної моделі кольорів у форматі RGB, що повністю описують характер аналізованого зображення.

\section{Висновки}

Для розпізнавання образів у системі дистанційного моніторингу станів посівів найефективнішим інструментом $\epsilon$ нейронні мережі, що обумовлюється їх здатністю перенавчатись у процесі роботи. При аналізі розподілу 
вхідних даних показано, що три міри центральної тенденції збігаються, тобто середнє практично дорівнює медіані і моді, а отже, всі вхідні дані розподілені за нормальним законом. Тому замість вибірки великого об'єму набору даних на вхід нейронної мережі доцільно подати значення середнього з обчислюваних статистичних характеристик для адитивної моделі кольорів у форматі RGB, що повністю опишуть характер аналізованого зображення.

\section{Лiтература}

1. Гмурман B.E. Теория вероятностей и математическая статистика. - Москва, Высш.шк., 2003. - 479 с.

2. Кибзун А.И. Теория вероятностей и математическая статистика. базовый курс с примерами и задачами / А.И. Кибзун, Е.Р. Горяинова, А.В. Наумов, А.Н. Сиротин. Москва : Физматлит, 2002. - $224 \mathrm{c}$.

3. Лисенко В.П. Системи штучного інтелекту: нечітка логіка, нейронні мережі, нечіткі нейронні мережі, генетичний алгоритм / В.П. Лисенко, В.М. Решетюк, В.М. Штепа, Н.А. Заєць та ін. - Київ : НУБІП України, 2014. - 336 с.

4. Хайкин С. Нейронные сети: полный курс, 2-е издание. Пер. с англ. - Москва : Изд. дом «Вильямс», 2006. - 1104 с.

5. Нейронные сети. StatSoft. Электронный учебник по статистике [Электронный peсурс]. — Режим доступа : http://www.statsoft.ru/home/textbook/modules/stneunet.html. 